mediated $\mathrm{Ca}^{2+}$ influx: first, a hyperpolarization-mediated block of $\mathrm{Ca}^{2+}$ influx does not affect the $\mathrm{Ca}^{2+}$ influx and secretion induced by depolarizing the cells with high $\mathrm{K}^{+}$. Second, hyperpolarization of bovine $\mathrm{CC}$ with the $\mathrm{K}^{+}$-selective ionophore valinomycin does not prevent nicotine-induced $\mathrm{Ca}^{2+}$ influx [37].

The results of the present study confirm another important role for AA in the stimulusresponse coupling. Endogenous AA and other UFAs generated in the physiological process through the action of a phosphatidylinositol-specific phospholipase $\mathrm{C}$ and the diacylglycerol-monoacylglycerol pathway and/or the action of a phospholipase $\mathrm{A}_{2}$ exert two different, opposed roles. On the one hand AA mediates the stimulation of the cellular response through activating phospholipase C [13] and PKC [17], mobilizing intracellular $\mathrm{Ca}^{2+}[13]$ and inducing fusion [38] and secretion [12]. This enhancing effect occurs downstream of signal-release coupling at a moment where the $\mathrm{Ca}^{2+}$ channels already have been opened. On the other hand, AA causes relaxation of bovine $\mathrm{CC}$ by directly blocking receptor-dependent $\mathrm{Ca}^{2+}$ channels and, thus, desensitizsing the cell for prolonged or repeated stimulation. Lipoxygenase products are essential for the release mechanism [12], but they do not block the nicotinic channel (Fig. 6 , see results).

The time factor decides about the role for AA in the physiological process of signal transduction. Early in the signal transduction AA displays a stimulating effect. In contrast late in the signal-response coupling - when the receptor-mediated $\mathrm{Ca}^{2+}$ influx already occurred - AA exerts an inhibiting role and introduces the relaxation of the cell.

Chimia 45 (1991) 49-52

(C) Schweiz. Chemiker-Verband; ISSN 0009-4293

\section{Molekularbiologische Methoden in der Lebensmittelanalytik}

\author{
Urs Candrian und Jürg Lüthy*
}

Abstract. Recombinant DNA methods have been rareley used for the analysis of food samples. Since the introduction of the polymerase chain reaction in 1985, DNA analysis of food samples has become a practicable approach. This technique is capable of producing an exponential enrichment of a specific DNA sequence, greatly facilitating subsequent analytical procedures. Detection of infectious agents, identification of irradiated food, and determination of identity and contaminations are potential applications in food analysis. We develop PCR protocols for the detection of Listeria monocytogenes and Escherichia coli in food and clinical samples. The detection of wheat contamination in glutenfree products, which are intended for coeliac patients is another application currently under investigation.
Kernen for their expert technical assistance in isolating bovine adrenal medulla cells and measuring $\left[\mathrm{Ca}^{2+}\right]_{i}$ the Swiss National Science Foundation and by the Central Laboratory of the Blood Transfusion Service of Received: December 7, 1990

D.L. Kilpatrick, R.J. Slepetis, J.J. Corcoran, N Kirshner, J. Neurochem. 1982, 38, 427.

B.G. Livett, in 'Stimulus-Secretion Coupling in CRC Press, Boca Raton, Florida, 1987.

4] E.J. Forsberg, E. Rojas, H.B. Pollard, J. Biol.

Acta 1985, 846, 167.
W. Ku Microsc. Rev. 1989, 2, 349

7] A.G.Garcia, V.Cena, J.Frias, Actual.Chim.Ther 1984, 2, 165; V. Cena, G.P. Nicolas, P. Sanchez$1983,10,1455$.

8] R. Miledi, Proc. R. Soc. London, [Ser.] B 1980 209,447 ; W.L. Nastuk, in 'Synapses', Eds. G.A. Glasgow, 1977,p. 177; J. Siara, J.P. Ruppersberg, R. Rüdel, Pflügers Arch, 1990, 415, 701 .

O. Thastrup, Agents Actions 1990, 29,8; Y. Goh $1990,166,1346$; L. S. Kao, N. S. Cheung, $J$ Neurochem. 1990, 54, 1972.

10] P. Zahter, M. Reist, K. Rosenheck, Biochim. Biophys. Acta 1986, 877, 372

B. Rindlisbacher, M. Reist, P. Zahler, Biochim Biophys. Acta 1987, 905, 349.

Zahler, J. Neurochem. 1990, S4, 1247. phys. Res. Conmun. 1990, 169, 773.

1) P. M. Rubin in 'Receptor Biochemistry and Methodology', Ed. J. W. Putney, Liss, New York, 1986, Vol. 7, p. 163

Farese, Am. J. Med Sci 1988, 296, 223. 192, 189. Chem. 1986, 261, 4915.

CHIMIA 45 (1491) Nr.1/2 (Jamuar/Frhruirr)

[17] Y. Koda, A. Wada, N. Yanagihara, Y. Uezono, F. Izumi, Neuroscience 1989, 29, 495.

[18] I. Lotan, N. Dascal, Z. Naor, R. Boton, FEBS Lett. 1990, 267, 25.

[19] P. Arkhammar, T. Nilsson, M. Welsh, N. Welsh. P.O. Berggren, Biochem. I. 1989, 264, 207; P. O. Berggren, P. Arkhammar, T. Nilsson, Biochem. Biophys. Res. Commun. 1989, $165,416$.

[20] D.C.C. Wan, S.J. Bunn, B.G. Livett. J. Neurochem. $1989,53,1219$

[21] W.S. Lai, T. B. Rogers, E.E. El-Fakahany, Biochem. J. 1990, 267, 23.

[22] R.L. Huganir, A.H. Delcour, P. Greengard, G.P. Hess, Naure (London) 1986, 321.774.

[23] D. Kim, D. E. Clapham, Science 1989, 244, 1174.

[24] R.W. Ordway, J.V. Walsh, J.J. Singer, Science $1989,244,1176$.

[25] S. C. Chow, M. Jondal, J. Biol. Chem. 1990, 26.5, 902.

[26] H.W. Alila, R.A. Corradino, W. Hansel, Proslaglandins 1990, 39, 481; J. Corado, F. Le Deist, A. Fischer, Cell. Immunol. 1990, 126, 245; T. Tohmatsu, S. Nakashima, Y. Nozawa, Biochim. Biophlys. Acta 1989, 1012, 97; M. A. Kowilskil. A. K. Rao, J. Disa, Biochem.J.1988, 253, 255; L. Beaumier, N. Faucher, P.H. Naccache, FEBS Lett. 1987, 22l, 289.

[27] D. Piomelli, J. K. T. Wang, T. S. Silura, A. C. Naim, A. J. Czernik, Proc. Natl. Acad. Sci. USA $1989,86,8550$

[28] S. C. Chow, I. J. Ansotegui, M. Jondal, Biochem. J. 1990, 267, 727.

[29] A. Greenberg, O.Zinder, Cell Tissue Re's. 1982, 226,655 .

[30] S.P. Wilson, J. Neurosci. Meth. 1987, 19, 163.

[31] B.G. Livett, Physiol. Rev. 1984, 64, 1103

[32] P.I. Lelkes, J.E. Friedman, K. Rosenheck, J. Neurosci. Meth. 1985, 13, 249.

[33] W.J. Dixon, F.J. Massey, 'Introduction to Statistical Analysis', 3rd edn., McGraw-Hill Kogakusha Ltd., Tokyo, 1969, p. 328.

[34] G. Grynkiewicz, M. Poenie, R.Y. Tsien, J. Biol. Chem. 1985, 260, 3440 .

[35] D.A. Deranleau, E. Stüssi, Rev. Sci. Instr. 1987, $58,1840$.

[36] M.U. Ehrengruber, Lizentiatsarbeit, Universität Bern, 1990.

[37] M.U. Ehrengruber, P. Zahler, in preparation.

[38] S.M. Ali. M.J. Geisow, R.D. Burgoyne, Nature (London) 1989, 340, 313.

\section{Einleitung}

Fortschritte in den Methoden der Molekularbiologie und der Biotechnologie führten in den letzten Jahren zu stark erweiterten Möglichkeiten für die sogenannte DNA Diagnostik [1]. Fundamental für dieses Gebiet sind die Definition von NukleinsäureSequenzen, die sich als zu bestimmende Parameter eignen, und die Entwicklung von Methoden, die es erlauben, die spezifischen DNA-Sequenzen zu erfassen. Neben Hybridisierungstechniken steht heute die Polymerase-Kettenreaktion (Polymerase Chain Reaction, PCR) in Zentrum. Die PCR ist

\section{* Korrespondenz: PD Dr. J. Lüthy}

Institut für Biochemie Laboratorium für Le-

bensmittelchemie

Universität Bern

Freiestr. 3, CH-3012 Bern 
mediated $\mathrm{Ca}^{2+}$ influx: first, a hyperpolarization-mediated block of $\mathrm{Ca}^{2+}$ influx does not affect the $\mathrm{Ca}^{2+}$ influx and secretion induced by depolarizing the cells with high $\mathrm{K}^{+}$. Second, hyperpolarization of bovine $\mathrm{CC}$ with the $\mathrm{K}^{+}$-selective ionophore valinomycin does not prevent nicotine-induced $\mathrm{Ca}^{2+}$ influx [37].

The results of the present study confirm another important role for AA in the stimulusresponse coupling. Endogenous AA and other UFAs generated in the physiological process through the action of a phosphatidylinositol-specific phospholipase $\mathrm{C}$ and the diacylglycerol-monoacylglycerol pathway and/or the action of a phospholipase $\mathrm{A}_{2}$ exert two different, opposed roles. On the one hand AA mediates the stimulation of the cellular response through activating phospholipase C [13] and PKC [17], mobilizing intracellular $\mathrm{Ca}^{2+}[13]$ and inducing fusion [38] and secretion [12]. This enhancing effect occurs downstream of signal-release coupling at a moment where the $\mathrm{Ca}^{2+}$ channels already have been opened. On the other hand, AA causes relaxation of bovine $\mathrm{CC}$ by directly blocking receptor-dependent $\mathrm{Ca}^{2+}$ channels and, thus, desensitizsing the cell for prolonged or repeated stimulation. Lipoxygenase products are essential for the release mechanism [12], but they do not block the nicotinic channel (Fig. 6 , see results).

The time factor decides about the role for AA in the physiological process of signal transduction. Early in the signal transduction AA displays a stimulating effect. In contrast late in the signal-response coupling - when the receptor-mediated $\mathrm{Ca}^{2+}$ influx already occurred - AA exerts an inhibiting role and introduces the relaxation of the cell.

Chimia 45 (1991) 49-52

(C) Schweiz. Chemiker-Verband; ISSN 0009-4293

\section{Molekularbiologische Methoden in der Lebensmittelanalytik}

\author{
Urs Candrian und Jürg Lüthy*
}

Abstract. Recombinant DNA methods have been rareley used for the analysis of food samples. Since the introduction of the polymerase chain reaction in 1985, DNA analysis of food samples has become a practicable approach. This technique is capable of producing an exponential enrichment of a specific DNA sequence, greatly facilitating subsequent analytical procedures. Detection of infectious agents, identification of irradiated food, and determination of identity and contaminations are potential applications in food analysis. We develop PCR protocols for the detection of Listeria monocytogenes and Escherichia coli in food and clinical samples. The detection of wheat contamination in glutenfree products, which are intended for coeliac patients is another application currently under investigation.
Kernen for their expert technical assistance in isolating bovine adrenal medulla cells and measuring $\left[\mathrm{Ca}^{2+}\right]_{i}$ the Swiss National Science Foundation and by the Central Laboratory of the Blood Transfusion Service of Received: December 7, 1990

D.L. Kilpatrick, R.J. Slepetis, J.J. Corcoran, N Kirshner, J. Neurochem. 1982, 38, 427.

B.G. Livett, in 'Stimulus-Secretion Coupling in CRC Press, Boca Raton, Florida, 1987.

4] E.J. Forsberg, E. Rojas, H.B. Pollard, J. Biol.

Acta 1985, 846, 167.
W. Ku Microsc. Rev. 1989, 2, 349

7] A.G.Garcia, V.Cena, J.Frias, Actual.Chim.Ther 1984, 2, 165; V. Cena, G.P. Nicolas, P. Sanchez$1983,10,1455$.

8] R. Miledi, Proc. R. Soc. London, [Ser.] B 1980 209,447 ; W.L. Nastuk, in 'Synapses', Eds. G.A. Glasgow, 1977,p. 177; J. Siara, J.P. Ruppersberg, R. Rüdel, Pflügers Arch, 1990, 415, 701 .

O. Thastrup, Agents Actions 1990, 29,8; Y. Goh $1990,166,1346$; L. S. Kao, N. S. Cheung, $J$ Neurochem. 1990, 54, 1972.

10] P. Zahter, M. Reist, K. Rosenheck, Biochim. Biophys. Acta 1986, 877, 372

B. Rindlisbacher, M. Reist, P. Zahler, Biochim Biophys. Acta 1987, 905, 349.

Zahler, J. Neurochem. 1990, S4, 1247. phys. Res. Conmun. 1990, 169, 773.

1) P. M. Rubin in 'Receptor Biochemistry and Methodology', Ed. J. W. Putney, Liss, New York, 1986, Vol. 7, p. 163

Farese, Am. J. Med Sci 1988, 296, 223. 192, 189. Chem. 1986, 261, 4915.

CHIMIA 45 (1491) Nr.1/2 (Jamuar/Frhruirr)

[17] Y. Koda, A. Wada, N. Yanagihara, Y. Uezono, F. Izumi, Neuroscience 1989, 29, 495.

[18] I. Lotan, N. Dascal, Z. Naor, R. Boton, FEBS Lett. 1990, 267, 25.

[19] P. Arkhammar, T. Nilsson, M. Welsh, N. Welsh. P.O. Berggren, Biochem. I. 1989, 264, 207; P. O. Berggren, P. Arkhammar, T. Nilsson, Biochem. Biophys. Res. Commun. 1989, $165,416$.

[20] D.C.C. Wan, S.J. Bunn, B.G. Livett. J. Neurochem. $1989,53,1219$

[21] W.S. Lai, T. B. Rogers, E.E. El-Fakahany, Biochem. J. 1990, 267, 23.

[22] R.L. Huganir, A.H. Delcour, P. Greengard, G.P. Hess, Naure (London) 1986, 321.774.

[23] D. Kim, D. E. Clapham, Science 1989, 244, 1174.

[24] R.W. Ordway, J.V. Walsh, J.J. Singer, Science $1989,244,1176$.

[25] S. C. Chow, M. Jondal, J. Biol. Chem. 1990, 26.5, 902.

[26] H.W. Alila, R.A. Corradino, W. Hansel, Proslaglandins 1990, 39, 481; J. Corado, F. Le Deist, A. Fischer, Cell. Immunol. 1990, 126, 245; T. Tohmatsu, S. Nakashima, Y. Nozawa, Biochim. Biophlys. Acta 1989, 1012, 97; M. A. Kowilskil. A. K. Rao, J. Disa, Biochem.J.1988, 253, 255; L. Beaumier, N. Faucher, P.H. Naccache, FEBS Lett. 1987, 22l, 289.

[27] D. Piomelli, J. K. T. Wang, T. S. Silura, A. C. Naim, A. J. Czernik, Proc. Natl. Acad. Sci. USA $1989,86,8550$

[28] S. C. Chow, I. J. Ansotegui, M. Jondal, Biochem. J. 1990, 267, 727.

[29] A. Greenberg, O.Zinder, Cell Tissue Re's. 1982, 226,655 .

[30] S.P. Wilson, J. Neurosci. Meth. 1987, 19, 163.

[31] B.G. Livett, Physiol. Rev. 1984, 64, 1103

[32] P.I. Lelkes, J.E. Friedman, K. Rosenheck, J. Neurosci. Meth. 1985, 13, 249.

[33] W.J. Dixon, F.J. Massey, 'Introduction to Statistical Analysis', 3rd edn., McGraw-Hill Kogakusha Ltd., Tokyo, 1969, p. 328.

[34] G. Grynkiewicz, M. Poenie, R.Y. Tsien, J. Biol. Chem. 1985, 260, 3440 .

[35] D.A. Deranleau, E. Stüssi, Rev. Sci. Instr. 1987, $58,1840$.

[36] M.U. Ehrengruber, Lizentiatsarbeit, Universität Bern, 1990.

[37] M.U. Ehrengruber, P. Zahler, in preparation.

[38] S.M. Ali. M.J. Geisow, R.D. Burgoyne, Nature (London) 1989, 340, 313.

\section{Einleitung}

Fortschritte in den Methoden der Molekularbiologie und der Biotechnologie führten in den letzten Jahren zu stark erweiterten Möglichkeiten für die sogenannte DNA Diagnostik [1]. Fundamental für dieses Gebiet sind die Definition von NukleinsäureSequenzen, die sich als zu bestimmende Parameter eignen, und die Entwicklung von Methoden, die es erlauben, die spezifischen DNA-Sequenzen zu erfassen. Neben Hybridisierungstechniken steht heute die Polymerase-Kettenreaktion (Polymerase Chain Reaction, PCR) in Zentrum. Die PCR ist

\section{* Korrespondenz: PD Dr. J. Lüthy}

Institut für Biochemie Laboratorium für Le-

bensmittelchemie

Universität Bern

Freiestr. 3, CH-3012 Bern 
eine enzymatische in-vitro-Methode für die Produktion einer grossen Menge eines spezifischen DNA-Fragments von definierter Länge und Sequenz ausgehend von einer kleinen Menge komplexer Templat-DNA. Die enzymatische Vervielfältigung ('amplification') benötigt zwei OligonukleotidPrimer, die das zu vervielfältigende DNAFragment flankieren. Diese Primer sind so definiert, dass sie zu den komplementären Strängen der Ziel-DNA hybridisieren. Sie sind so orientiert, dass die Region zwischen den Primern mittels einer DNA-Polymerase neu synthetisiert werden kann. Dies führt zu einer Verdopplung der Ziel-DNA. Da auch die neusynthetisierte DNA wieder als Templat dienen kann, führen wiederholte Zyklen yon Hitzedenaturation der Ziel-DNA, Hybridisierung der Primer und anschliessender DNA-Neusynthese mit einer hitzestabile DNA-Polymerase zu einer exponentiellen Akkumulation der spezifischen ZielDNA [2]. Die Amplifikation der DNA erlaubt nachfolgend eine einfache Analyse z.B. mittels Agarose-Gelelektrophorese. Eine weitere wichtige Methode sind die sogenannten DNA-Fingerprints. Hochvariable Regionen menschlicher, tierischer oder auch pflanzlicher oder mikrobieller DNA liefern nach der Verdauung mit geeigneten Restriktionsendonukleasen ein Muster von verschieden grossen DNA-Fragmenten, die für ein einzelnes Individuum spezifisch sind [3].

Das Hauptgewicht der gegenwärtigen Forschung in unserem Laboratorium auf dem Gebiet der DNA-Diagnostik liegt beim Nachweis von pathogenen Mikroorganismen in Lebensmitteln und Wasser. Die Entwicklung eines Testsystems zum Erfassen von pathogenen Listeria monocytogenes ist am weitesten gediehen. Die Auswahl eines geeigneten Genes für die Definition von PCR-Primern spezifisch für L. monocytogenes war dabei nicht die schwierigste Aufgabe. Vielmehr kommt der Probenvorbereitung eine zentrale Rolle zu. Der Grund dafür ist die Tatsache, dass zahlreiche Substanzen die PCR hemmen können. Dazu gehören beispielsweise Kalzium, Phosphat und ionische Detergentien. Die Vermeidung falsch negativer Resultate durch die Entwicklung von standardisierten Protokollen für die Probenvorbereitung beruhend auf der Isolation intakter Bakterien nimmt daher in unserem Labor eine zentrale Rolle ein. Dieser Ansatz hat den Vorteil, dass die arbeitsintensive Isolation von DNA aus Probenmaterial wegfällt. Isolierte Bakterien können ohne grossen Aufwand mittels Standardmethoden aufgeschlossen werden und ohne Reinigungsschritte in der PCR eingesetzt werden. Eine Hemmung der Reaktion durch Zellbestandteile tritt erst bei sehr hohen Bakterienzahlen $>10^{6}$ auf und hat die Form eines Plateau-Effekts, resultiert also nicht in falsch negativen Resultaten.

Ein weiteres nicht zu unterschätzendes Problem bei der Anwendung der PCR ist das Auftreten von falsch positiven Resultaten bedingt durch Kontamination mit Reaktionsprodukt von vorangehenden Reaktionen. Dies kann in erster Linie durch das strikte Befolgen einer Reihe von Vorsichtsmassnahmen verhindert werden [4]. Dazu gehören in erster Linie die räumliche Trennung der Vorbereitungsarbeiten von der Analytik der PCR-Produkte. Eine weitere Möglichkeit, die in unserem Labor entwikkelt wurde, ist die Dekontamination der Reaktionsmischungen vor der Templatzugabe mittels Verdauung mit Restriktionsenzymen oder DNasel [5]. Die resultierenden Strangbrïche verhindern eine Amplifikation der kontaminierenden DNA in der PCR. Eine ähnliche Methode, die sogar eine Dekontamination nach der Templatzugabe ermöglicht, wurde von Longo et al. [6] entwickelt: In der Amplifikationsreaktion wird dTTP durch dUTP ersetzt. Dies erlaubt die Verdauung der fertigen Reaktionsmischungen vor dem Start der Amplifikation mit dem Enzym Uracil-DNA-Glykosylase. Dieses Reparatur-Enzym entfernt Uracil aus DNA und führt zu Strangbrüchen. Die Brauchbarkeit dieses Systems in der Praxis muss allerdings erst noch,überprüft werden und dürfte vor allem von der Effizienz der enzymatischen Reaktion abhängen. Neben den PCR-Systemen für den Nachweis von $L$. monocytogenes verfügen wir über eine Reihe von PCR-Testsystemen zum Nachweis von Escherichia coli einschliesslich der Identifikation enterotoxigener Stämme. Ein weiteres Projekt, das im Rahmen dieser kurzen Übersichtsarbeit vorgestellt werden soll, betrifft den Nachweis von Weizenkontaminationen in Mehlen anderer Getreide und in Produkten, die ohne Weizen hergestellt wurden.

\section{Nachweis und Identifikation von Listeria monocytogenes}

L. monocytogenes ist schon seit langem bekannt als Verursacher von sporadisch vorkommenden Infektionen beim Menschen, wobei in erster Linie immungeschwächte Personen, Neugeborene und Schwangere betroffen sein können [7]. Im Laufe der letzten Jahrzehnte wurde eine Zunahme der Listeriose-Erkrankungen beim Menschen und schliesslich in den 80er Jahren eine Anzahl von lebensmittelbedingten Listeriose-Ausbruichen in den USA und in Europa beobachtet. Auch in der Schweiz kam es zu einem Ausbruch [8], der durch kontaminierten Käse der Sorte Vacherin Mont-d'Or verursacht wurde und über 30 Todesopfer forderte. Das Hauptproblem bei der Analyse von Lebensmitteln auf Kontamination mit L. monocytogenes ist der Zeitaufwand, der für die klassische selektive Kultivierungsmethode benötigt wird. Ohne Serotypisierung vergeht mindestens eine Woche bis das Resultat vorliegt. In den meisten Fällen ist das betreffende Lebensmittel zu diesem Zeitpunkt bereits verzehrt. Es besteht daher ein grosses Bedürfnis nach einer schnellen Methode. Die PCR bietet die Voraussetzungen, um diese Forderung zu erfüllen. Bei der

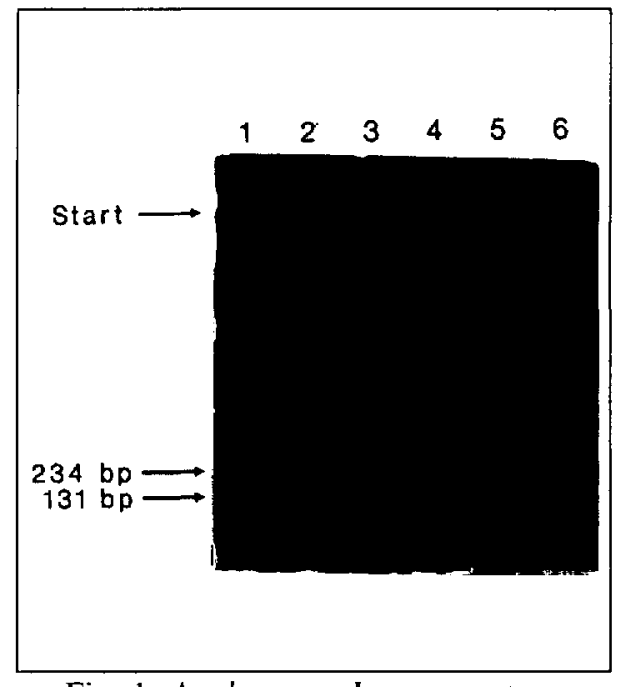

Fig. 1. Analyse von L. monocytogenes Amplifikationsprodukten mittels Agarosegelelektrophorese. Ca. 100'000 Listerien wurden mittels Lysozym/Proteinase-K-Behandlung aufgeschlossen und wie beschrieben 40 hlyA- und iap-PCR Zyklen unterworfen [9]. Bahnen: 1: L. monocytogenes $1 /$ $2 \mathrm{a} ; 2$ : L. monocytogenes $1 / 2 \mathrm{~b} ; 3, L$. monocytogenes $4 \mathrm{~b} ; 4$ : L. monocytogenes $1 / 2 \mathrm{c}$; 5:L.monocytogenes 4a; 6: Negativkontrolle (L. innocua). Fragmente: 234 Basenpaare (bp), hlyA; 131 bp, iap.

Auswahl geeigneter Zielgene für die Primerdefinition konzentrierten wir uns auf bekannte Virulenzfaktoren von $L$. monocytogenes. Dazu gehört die Fähigkeit hämolytisches Listeriolysin $\mathrm{O}$ zu produzieren [9]. Das für Listeriolysin O kodierende hlyAGen wurde sequenziert [10]. Eine weitere Virulenzdeterminante ist die Produktion eines wichtigen extrazellulären Proteins, das eine Rolle bei der Invasion von Phagozyten spielt (invasion-associated protein, iap-Gen) und dessen DNA-Sequenz ebenfalls vorliegt [11]. Die Verwendung dieser beiden Gene für die Ausarbeitung eines PCR-Tests erlaubte die Entwicklung eines Systems spezifisch für L. monocytogenes [12]. Die hlyAPrimer definieren ein 234 Basenpaar-Fragment aus dem $h l y A$-Gen, die iap-Primer ein 131 Basenpaar-Fragment aus dem iap-Gen. Beide DNA-Amplifikationen können in einer einzigen Reaktion durchgeführt werden [12]. In Fig. 1, Bahnen $1-4$ sind die Amplifikationsprodukte von vier verschiedenen L. monocytogenes Serotypen gezeigt. Alle vier Serotypen $-1 / 2 \mathrm{a}, 1 / 2 \mathrm{~b}, 1 / 2 \mathrm{c}$ und $4 \mathrm{~b}-$ enthalten offensichtlich beide Gene. Im Gegensatz dazu verfügt der Serotyp 4a (Fig. 1 , Bahn 5) nur über das hlyA-Gen während das iap-Gen fehlt. Dieser Serotyp muss daher aufgrund des gegenwärtigen Wissensstandes als nicht pathogen bezeichnet werden [11]. Bisher wurden mit Ausnahme von L. grayi, L. murrayi und $L$. welshimeri sämtliche Listeria-Spezies und Serotypen mit den beschriebenen PCR-Testen geprüft. Mit Ausnahme der Serotypen 4a und $4 c$ waren sämtliche Serotypen von $L$. monocytogenes positiv für beide Virulenzgene. Die Serotypen $4 \mathrm{a}$ und $4 \mathrm{c}$ enthalten lediglich das hlyA Gen während das iap-Gen fehlt. Negativ in 


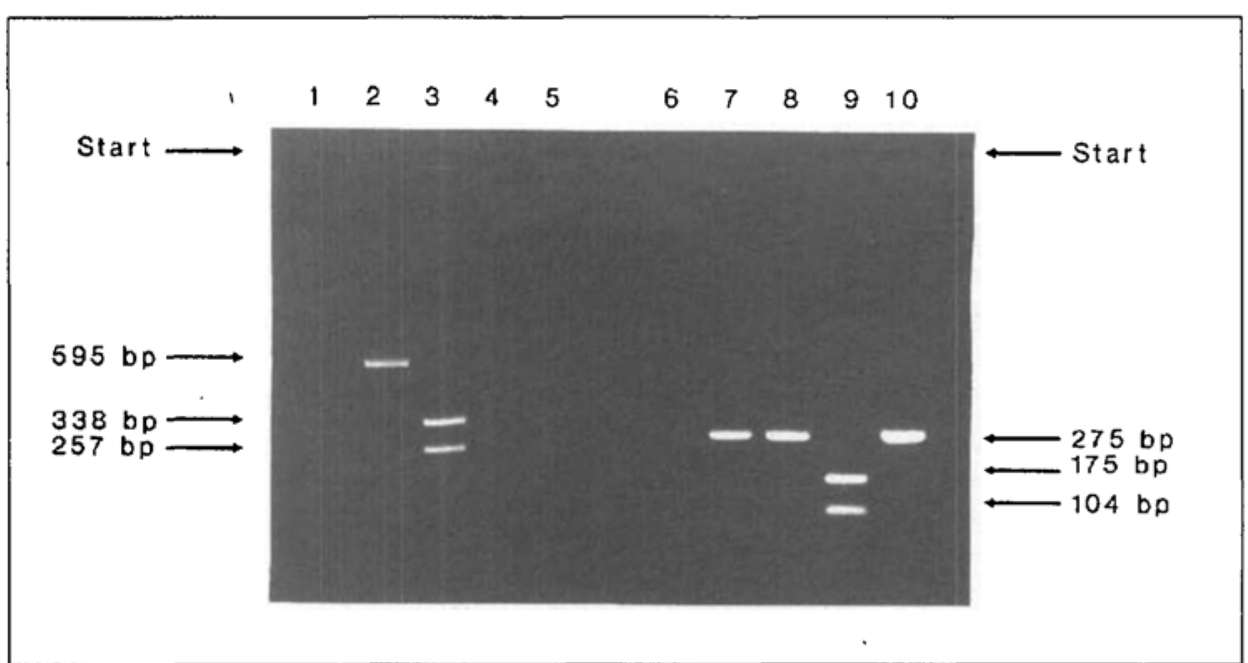

Fig. 2. Analyse von Escherichia coli Amplifikationsprodukten mittels Agarosegelelektrophorese. $\mathrm{Ca}$. 100'000 E. coli wurden mittels Lysozym/Proteinase-K-Behandlung aufgeschlossen und wie beschrieben 40 malB- bezw. LTI-PCR-Zyklen unterworfen [10]. Bahnen: 1: Negativekontrolle (keine Bakterien) ma/B-PCR; 2: E. coli Stamm, malB-PCR; 3: ECoRI-Verdauung des Amplifikationsproduktes aus Bahn 1; 4: Salmonella typhimurium, malB-PCR; 5: Enterobacter aerogenes, malB-PCR; 6: Negativkontrolle (keine Bakterien) LTI-PCR; 7, 8: $\mathrm{LTI}^{+}$E. coli Stämme (zwei verschiedene Allele), LTI-PCR; 9, 10: CfoI-Verdauung der Amplifikationsprodukte aus den Bahnen 5 und 6. Fragmente: 595 Basenpaare (bp), malB; 338+257 bp, EcoRI-Fragmente des malB-Produktes; 275 bp, LTI; $171+104$ bp, Cfol-Fragmente des LTI-Produktes (nur ein Allel).

beiden Systemen waren die Serotypen der Spezies $L$. innocua, $L$. ivanovii und $L$. seeligeri. Gegenwärtig entwickeln wir Protokolle zum direkten Nachweis von L. monocytogenes in Lebensmitteln mit den beschriebenen PCR-Testen. Ein erstes Protokoll, das auf der Isolation der Bakterien mittels Zentrifugation beruht, erlaubt den Nachweis von einem Bakterium pro $\mathrm{ml}$ roher oder pasteurisierter Milch innert $24 \mathrm{~h}$ [12].

\section{Nachweis von Escherichia coli und Identifikation von enterotoxigenen Stämmen}

E. coli ist ein wichtiger Fäkalienkeim und sein Vorkommen in Lebensmitteln und Trinkwasser weist auf Fäkalienkontakt und ungenügende Hygiene bei der Handhabung hin. Der gegenwärtige Stand der Technik erlaubt eine rasche und einfache Bestimmung dieses Keims mittels klassischer Kultivierungsmethoden. Zu Vergleichszwecken und um über ein Modellsystem für die Entwicklung von PCR-Tests für pathogene $E$. coli zu verfügen, entschieden wir uns, trotzdem ein speziesspezifisches PCR System für $E$. coli auszuarbeiten. Als Zielsequenz für den Nachweis wählten wir eine Region im malB-Operon. Diese Region weist über $80 \%$ Basenhomologie mit den entsprechenden Regionen von Salmonella typhimurium und Enterobacter aerogenes auf. Durch eine geeignete Definition des Primerpaares für die PCR in kleinen Sequenzabschnitten mit erhöhter Variabiltät gelang es uns, einen PCR-Test auszuarbeiten, der nur $E$. coli erfasst [13]. In Fig. 2, Bahn 2 wird das von einem E. coli Stamm erhaltene 595 Basenpaare lange Amplifikationsprodukt gezeigt.
Wie aus den Bahnen 4 und 5 hervorgeht, wird Enterobacter aerogenes kein Amplifikationsprodukt erhalten. Bei der Bahn 3 handelt es sich um die Identifikation des DNAFragments aus Bahn 2 mittels Restriktionsanalyse: Verdauung mit $E c o$ RI liefert zwei Bruchstücke von aufgrund der bekannten Sequenzdaten erwarteter Grösse. Als alternative Identifikationsmethode würde sich die Hybridisierung mit einer DNA-Sonde eignen [13]. Gegenwärtig arbeiten wir an Protokollen zum direkten PCR-Nachweis von $E$. coli in Wasser und Käse. Ein brauchbares Arbeitsprotokoll für Oberflächenwasser, das auf der Isolation von E. coli mittels Filtration und Zentrifugation beruht, lieferte bereits semiquantitative, mit der klassischen Methode durchaus vergleichbare Resultate über einen Bereich von $<100$ $>2000$ Zellen pro $100 \mathrm{ml}$ Wasser. Die PCRMethodik ist in diesem Fall der klassischen Methode bezüglich Schnelligkeit und Einfachheit in der Durchführung nicht überlegen, erfasst aber problemlos auch Stämme mit biochemisch unüblichem Verhalten wie $\mathrm{lac}^{-}$und $\mathrm{MUG}^{-}$[13] . Der Hauptvorteil der PCR-Methodik liegt jedoch in einer anderen Richtung. Neben den üblichen nicht pathogenen $E$. coli Stämmen sind zahlreiche Diarrhoe erregende Stämme bekannt. Dazu gehören auch die enterotoxigenen $E$. coli, die verschiedene Typen von Enterotoxinen bilden können. Die für diese Proteine kodierenden Gene sind in der Regel auf Plasmiden lokalisiert. Gegenwärtig werden bei Routineanalysen derartige Stämme aus zwei Gründen nicht erfasst. Erstens können die zurzeit gültigen Kultivierungsmethoden aus Lebensmitteln, bedingt durch die Selektion mit DNA von Salmonella typhimurium und mit toxischen Chemikalien und hoher Temperatur, einen physiologischen Stress bewirken, wobei bei der Zellteilung unnötige, den Stoffwechsel belastende genetische Informationen verloren gehen können. Dies bedeutet den Verlust von Plasmiden und führt dazu, dass enterotoxigene Stämme nicht als solche erkannt werden. Der zweite Grund ist, dass die gegenwärtigen Standardmethoden zum Erkennen von Enterotoxinen auf Tierversuchen beruhen und immunologische Tests nur sehr langsam aufkommen und sich zurzeit nur fürdie Analyse von Reinstämmen eignen. Wir entwickelten daher in unserem Labor PCR-Teste zum Nachweis der Gene für die Produktion von hitzelabilem Toxin Typ I [14] und hitzestabilem Toxin Typ I [15]. Von beiden Genen sind verschiedene Allele bekannt. Beide PCR-Tests erkennen alle bekannten Allele und die Primer wurden so definiert, dass die verschiedenen Allele mittels Restriktionsanalyse unterschieden werden können [14][15]. In Fig. 2, Bahnen 7 und 8 , sind als Beispiel die Amplifikationsprodukte (275 Basenpaare lang) von zwei E. coli Stämmen mit der genetischen Information für die Produktion von hitzelabilem Toxin Typ 1 gezeigt. Die Restriktionsanalyse mittels CfoI (Fig. 2, Bahn 9 is. Bahn I0) zeigt, dass es sich dabei um zwei verschiedene Allele handelt, von denen nur eines die Restriktionsstelle für CfoI aufweist. Zur Validierung dieser Systeme testeten wireine Reihe enterotoxigener $E$. coli Stämme mittels PCR und ELISA (enzyme-linked immunosorbent assay). Wie aus der Tab. hervorgeht, fanden wir eine perfekte Korrelation zwischen genetischer Information (PCR) und tatsächlicher Enterotoxinproduktion (ELISA). Wir verfügen damit über PCR-Tests, die eine direkte Analyse von Lebensmittelproben auf enterotoxigene $E$. coli erlauben, ohne dass die Gefahr von Plasmidverlusten

Tabelle. Analyse von enterotorigenen Escherichia coli mit LTI- und STI-PCR ${ }^{a}$ ) und mit immumologischen Testen auf Enterotoxinproduktion

\begin{tabular}{lll}
\hline Charakterisierte Stämme & PCR & Immunol. Test \\
\cline { 2 - 3 } $\begin{array}{l}\text { Anzahl } \\
\text { Toxintyp }\end{array}$ & $\begin{array}{l}\text { Anzahl } \\
\text { positiv }\end{array}$ & $\begin{array}{l}\text { Anzahl } \\
\text { getested }\end{array}$ \\
\hline $\mathrm{LTI}^{+}$ & $1 / 1$ & $1 / 1$ \\
$\mathrm{LT}^{+}$ & $\left(1 / 14^{\mathrm{b}}\right.$ ) & $11 / 14^{\mathrm{b}}$ ) \\
$\mathrm{LT}^{-}$ & $0 / 7$ & $0 / 7$ \\
$\mathrm{LT}^{2}$ & $0 / 3$ & $0 / 3$ \\
$\mathrm{ST}^{+}$ & $\left.4 / 6^{\mathrm{b}}\right)$ & $\left.4 / 6^{\mathrm{b}}\right)$ \\
$\mathrm{ST}^{+}$ & $6 / 6$ & $6 / 6$ \\
$\mathrm{ST}^{-}$ & $0 / 9$ & $0 / 9$ \\
$\mathrm{ST}^{+}$ & $0 / 6$ & $0 / 6$ \\
\hline
\end{tabular}

a) LT, hitzelabiles Enterotoxin; ST, hitzestabiles Enterotoxin; 1, Typ I.

b) Einige Stämme, die uns als Enterotoxin-Produzenten beschrieben wurden, wiesen weder die entsprechende genetische Information auf, noch waren sie in der Lage tatsächlich Toxin zu produzieren. Im Fall der LT Stämme kann die Produktion von LT Typ II nicht ausgeschlossen werden. 
besteht und ohne den Einsatz von Tierversuchen.

\section{Nachweis von Weizenkontaminatio- nen in glutenfreien Lebensmitteln}

Zoeliakie, eine der häufigsten chronischen gastrointestinalen Erkrankungen von Kindern und Erwachsenen, wird definiert als permanente Intoleranz gegen das in Weizen und Roggen vorkommende Klebereiweiss Gluten. Davon Betroffene sind lebenslang auf eine glutenfreie Diät angewiesen. Die Glutenproteine des Weizens können aufgrund unterschiedlicher elektrophoretischer Mobilität fraktioniert werden $(\alpha-, \beta$, $\gamma$ und $\omega$-Gliadine). Ähnliche Proteine, die vermutlich ebenfalls Krankheitssymptome verursachen können, kommen im Hafer und in der Gerste vor. Dagegen werden beispielsweise Mais und Reis von Zoeliakiepatienten problemlos toleriert. Firmen, die glutenfreie Produkte herstellen, verwenden nichttoxische Getreidearten und/oder gliadinfreie Weizenstärke. Da diese Firmen in der Regel auch weizenhaltige Produkte für die Normalbevölkerung herstellen, muss bei weizenfreien Mehlen und Produkten mit Weizenkontamination gerechnet werden Selbst eine Kontamination, die weniger als $1 \%$ beträgt, kann für Zoeliakiepatienten noch eine schädigende Wirkung haben. Diese Situation und die Tatsache, dass sich bisher kein in diesem Bereich brauchbarer immunologischer Gliadinbestimmungstest (z.B. ELISA) in der Praxis durchgesetzt hat, veranlasste uns, ein Nachweissystem für Weizen, das auf dem Erkennen von WeizenDNA mittels der PCR beruht, zu entwickeln. Als Zielgene für die PCR wurden die $\alpha / \beta$ Gliadingene ausgewählt. Dafür war nicht ihre Beziehung zum toxischen Prinzip ausschlaggebend, sondern die hohe Kopienzahl, die im Weizengenom vorhanden ist. Diese Tatsache erleichtert wegen der prinzipiell höheren Anzahl Kopien der ZielDNA die Entwicklung eines sensitiven Tests.

Die PCR Primer wurden wie folgt ausgewählt: Alle bekannten $\alpha / \beta$-Gliadingensequenzen wurden auf Regionen maximaler Homologie untersucht. Obwohl signifikante Sequenzheterologien festgestellt wurden, konnten zwei hochkonservierte, 500-600 Basenpaare auseinanderliegende Regionen gefunden werden. Einer dieser konservierten Sequenzabschnitte kodiert für das von Wieser et al. [16] beschriebene Peptid B 3142 das möglicherweise die toxische GliadinAminosäure-Sequenz enthält. Je ein Primer wurde in diesen konservierten Regionen definiert. Vorläufige Resultate zeigen, dass dieses Primerpaar im PCR Prozess mi Weizen-DNA ein etwa 500-600 Basenpaare langes Fragment ergeben, das mittels Restriktionsanalyse als spezifisch für Weizen erkannt werden konnte. Weder mit Roggen-, Mais-, noch Reis-DNA wurde dieses Fragment erhalten. Erste Experimente mit Mischungen von Roggen und Weizen ergaben eine Nachweisgrenze für Weizen von $<0.1 \%$. Dieses System scheint daher geeig- net zu sein, um Weizen in anderen Mehlen nachweisen zu könne. Dagegen ergaben Vorversuche, dass die DNA in Brot sehr stark degradiert ist und die mittlere Länge weniger als 200 Basenpaare beträgt. Für die Analyse von gebackenen Produkten müsste daher ein PCR-System ausgearbeitet werden, in dem ein Fragment $<200$ Basenpaare amplifiziert wird. Entsprechende Experimente sind geplant.

\section{Schlussfolgerungen}

Unsere Experimente belegen die interessanten Anwendungsmöglichkeiten der PCR in der Lebensmittelanalytik. Grosse Vorteile gegenuiber der klassischen Methodik sind vor allem auf dem Gebiet der LebensmittelMikrobiologie zu erwarten. Der mögliche Verzicht auf Kultivierungsschritte eliminiert die Gefahr von Verlusten der genetischen Information von Virulenzfaktoren. Dies wird deutlich am Beispiel der enterotoxigenen $E$. coli ist aber auch bei Listerien möglich [17] Ein weiterer Vorteil ist die Tatsache, dass auch lebensfähige, aber unter den üblichen selektiven Anreicherungsbedingungen nicht kultivierbare, bakterielle Zellen erfasst werden. In diesem Zusammenhang muss auch die Problematik des Nachweises von toten und damit ungefährlichen Bakterien angesprochen werden. Unser Ansatz für die direkte Analyse von Lebensmitteln beruht nicht auf der Isolierung von DNA sondern von intakten Bakterienzellen mittels Zentrifugation. Da abgestorbene Bakterien autolysieren, erfasst unsere Methodik vermutlich keine toten Bakterien. Die Richtigkeit dieser Überlegung testen wir gegenwärtig im Experiment. Eine alternative Lösung dieses Problems ist der Einsatz von RNA-PCR, an welcher wir ebenfalls arbeiten. Am Beispiel der enterotoxigenen $E$. coli wird deutlich [18], dass dank der PCRMethodik ein Ersatz von Tierversuchen möglich ist, was aus ethischen Gründen angestrebt werden sollte. Ein noch nicht zufriedenstellend gelöstes Problem bei der PCR-Technologie ist die Quantifizierung der Resultate. Es bestehen jedoch verschiedene Lösungsansätze und es ist damit zu rechnen, dass in nicht allzulanger Zeit ein brauchbares Vorgehen zur Quantifizierung vorliegt. Eine in unserem Labor noch nicht eingesetzte Methodik ist das DNA-Fingerprinting. Diese Methode sollte es erlauben, nicht nur Bakteriumspezies sondern auch einzelne Stämme einer Spezies zu unterscheiden [19]. Dies dürfte besonders bei epidemiologischen Untersuchungen und beim Auffinden der Kontaminationsquelle bei Ausbrüchen von bakteriell bedingten Lebensmittelintoxikationen von grosser Bedeutung sein. Eine PCR unterstützte Form des Fingerprintings wie es bei unserem Versuch zur Unterscheidung verschiedener Allele enterotoxigener $E$. coli angetönt ist, dürfte das Potential der Methode noch erhöhen. Zahlreiche weitere Anwendungsmöglichkeiten der DNA-Analytik sind auf dem Gebiet der Lebensmittelanalytik denkbar.
Eingegangen am 12. Dezember 1990

[1] U. Landegren, R. Kaiser, C.T. Caskey, L. Hood, 'DNA Diagnostics - Molecular Techniques and Automation', Science 1988, 242, 229.

[2] R. K. Saiki, D.H. Gelfand, S. Stoffel, S.J. Scharf, R. Higuchi, G.T. Horn, K.B. Mullis, H.A. Erlich, 'Primer Directed Enzymatic Amplification of DNA with a Thermostable DNA Polymerase', Science 1988, 239, 487 .

[3] A. H. Cawood, 'DNA Fingerprinting', Clin. Chem. 1989, 35, 1832.

[4] S. Kwok, R. Higuchi, 'Avoiding False Positives with PCR', Nature (London) 1989, 339, 237.

[5] B. Furrer, U. Candrian, P. Wieland, J. Lüthy, 'Improving PCR Efficiency', Nature (London) $1990,246,324$

[6] M.C. Longo, M.S. Berninger. J. L. Hartley, 'Use of Uracil DNA Glycosylase to Control Carryover Contamination in Polymerase Chain Reactions', Gene 1990. 93, 125.

[7] B. Lorber, 'Clinical Listeriosis-Implications for Pathogenesis', in 'Foodborne Listeriosis', Eds. A.J. Miller, J.L. Smith und G.A. Somkuti, Elsevier, Amsterdam, 1990, S. 41.

[8] J. Bille, 'Epidemiology of Human Listeriosis in Europe, with Special Reference to the Swiss Outbreak', in 'Foodborne Listeriosis', Eds. A.J. Miller, J.L. Smith und G.A. Somkuti, Elscvier, Amsterdam, 1990, S. 71.

[9] J. Mengaud, E. Gormley, M.F. Vicente, J. Chenevert, F. Baquero, J.C. Perez-Diaz, P. Cossart, 'Listeriolysin O Gene: Role in Virulence and Use as a DNA Probe', in 'Foodborne Listeriosis', Eds. A.J. Miller, J.L. Smith und G.A. Sonkuti, Elsevier, Amsterdam, 1990, S. 125.

[10] J. Mengaud, M.-F. Vicente, J. Chenevert, J.M. Pereira, C. Geoffroy, B. Gicquel-Sanzey, F. Baquero, J.-C. Perez-Diaz, P. Cossart, 'Expression in Escherichia coli and Sequence Analysis of the Lysteriolysin O Determinant of Listeria monocyrogenes', Infect. Immum. 1988, 56, 766

[11] S. Köhler, M. Leimeister-Wuichter, T. Chakraborty, F. Lottspeich, W. Goebel, 'The Gene Coding for Protein p60 of Listeria monocytogenes and Its Use as a Specific Probe for Listeria monocytogenes', Infect. Immin. 1990, 58, 1943.

[12] B. Furrer, U. Candrian, Ch. Höfelein, J. Lüthy, 'Detection and Identification of Listeria mo. nocytogenes in Cooked Sausage Products and in Milk by in vitro Amplification of Haemolysin Gene Fragments', J. Appl. Bact., in press.

[13] U. Candrian, B. Furrer, Ch. Höfelein, R. Meyer, M. Jermini, J. Lüthy, 'Detection of Escherichia coli and Identification of Enterotoxigenic Strains by Primer Directed Enzymatic Amplification of Specific DNA Sequences', Int. J. Food Microbiol., in press.

[14] B. Furrer, U. Candrian, J. Lüthy, 'Detection and Identification of $E$. coli Producing Heat-Labile Enterotoxin Type I by Enzymatic Amplification of a Specific DNA Fragment', Lett. Appl. Microbiol. 1990, 10, 31 .

15] U. Candrian, B. Furrer, Ch. Höfelein, J. Lüthy, -Use of Inosine-Containing Oligonucleotide Primers for Enzymatic Amplification of Different Alleles of the Gene Coding for Heat-Stable Toxin Type I of Enterotoxigenic E. coli', Appl. Environ. Microbiol., in press.

[16] H. Wieser, H.-D. Belitz, A. Ashkenazi, 'AminoAcid Sequence of the Coeliac Active Gliadin Peptide B 3142', Z. Lebensm.-Unters. Forsch. $1984,179,371$

[17] M. Leimeister-Wächter, W. Goebel, T. Chakraborty. 'Mutations Affecting Hemolysin Production in Listeria monocytogenes Located outside the Listeriolysin Gene', FEMS Microbiol. Lett. 1989, 65, 23.

[18] M.A. Montenegro, R. Helmuth, 'Molekularbiologische Methoden als Alternative zum Tierexperiment', Bundesgesundhbl. 1989, No. 8, 5347.

[19] R.J. Owen, 'Chromosomal DNA Fingerprinting - a New Method of Species and Strain Identification Applicable to Microbial Pathogens', Med. Microbiol. 1989, 30, 89 